\title{
An Unusual Case of Penetrating Ocular Trauma with a Pressure Cooker Whistle
}

\author{
Dinesh Kumar Thapa ${ }^{1}$, Shyam Vyas ${ }^{2}$, Rohit Saiju ${ }^{3}$, Pravesh Rajbhandari ${ }^{4}$, Basant Pant $^{5}$ \\ 1. Senior Resident Officer, Annapurna Neurological Institute and Allied Sciences, Maitighar, \\ Kathmandu. \\ 2. Consultant Ophthalmologist, Tilganga Eye Hospital, Kathmandu. \\ 3. Consultant Ophthalmologist \& Oculoplastic surgeon, Tilganga Eye Hospital, Kathmandu. \\ 4. Consultant Neurosurgeon, Annapurna Neurological Institute and Allied Sciences, Maitighar, \\ Kathmandu.
}

5. Chief Consultant Neurosurgeon, Annapurna Neurological Institute and Allied Sciences, Maitighar, Kathmandu.

\author{
Correspondence: \\ Dr. Dinesh K Thapa \\ Annapurna Neurological Institute and Allied Sciences \\ Maitighar, Kathmandu \\ E-mail: dineshkthapa@gmail.com \\ Phone: +9779843123518
}

Worldwide blindness in 1.6 million people is due to ocular trauma. Trauma is the most common cause of unilateral loss of vision in developing countries and about $5 \%$ of all bilateral blindness is directly due to trauma. In Nepal, ocular trauma is considered a major cause of unilateral blindness and caused $7.9 \%$ of all blindness in Nepal. It is the second leading cause of blindness after cataract. Pressure cooker is a cooking utensil that works with high pressure and heat, consuming less time and fuel but as seemingly easy, the trouble handling with it could be horrible. It may cause serious injury to someone nearby. Here by, we would like to report a case that could rarely happen in kitchen as a worst accident.

Key words: Orbital injury, facial injuries, traumatic blindness, foreign body in eye.

1

26 years lady presented to ER with the history of pressure cooker explosion in the kitchen with injury over the face and eye, which was happened few hours prior to presentation. Her vitals were stable with a pulse rate of $76 /$ minute, blood pressure 110/70 $\mathrm{mm} \mathrm{Hg}$ and Glasgow coma scale of 12 , she was hemodynamically stable. There was cut and lacerated wound over nasal bridge and both eyes (Fig1). Eye 29

Date submitted: $21 / 7 / 2019$

Date Accepted: 3/9/2019 examination showed excessive swelling on both side, there was no perception of light, visual acuity couldn't be assessed. There was no obvious foreign body seen outside. So wound was cleaned and sterile dressing was applied. She was administered tetanus toxoid, resuscitated with intravenous fluids and proper analgesia was given.

egneuro, Volume 01, Issue 02, 2019

DOI: https://doi.org/10.3126/egn.v1i2.25731 


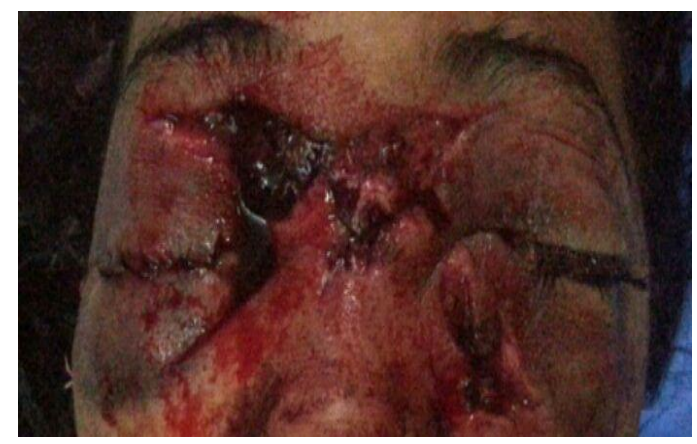

Figure 1: Multiple cut and lacerated wounds over face

Then CT and scan of head and face was obtained. There was hyperdense object seen in left eye globe causing significant artifact on CT scan, suggestive of metal foreign body to left eye globe. Though there was bony injury around the globe fortunately there was no injury to brain. Then she was shifted to ICU and emergency evacuation of the object was planned. Team of opththalmologist and oculoplastic surgeons were involved and the foreign body was removed along with enucleation of Left eye. The wound over the adjacent site and nasal bridge was closed in aesthetic way.
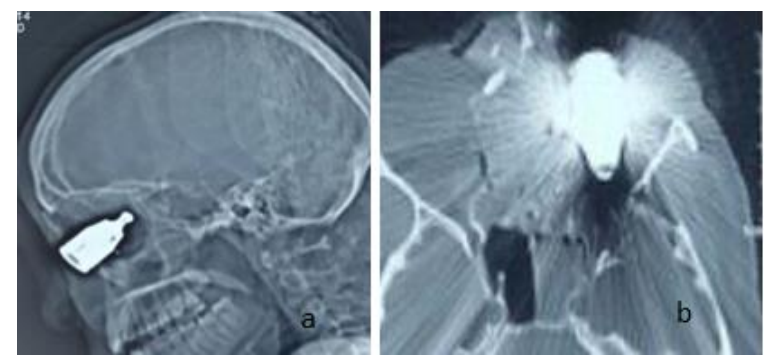

Figure 2 a and b: X-ray Skull lateral and CT orbit axial; showing hyperdense metallic foreign body lodging in left eye globe causing significant artifact

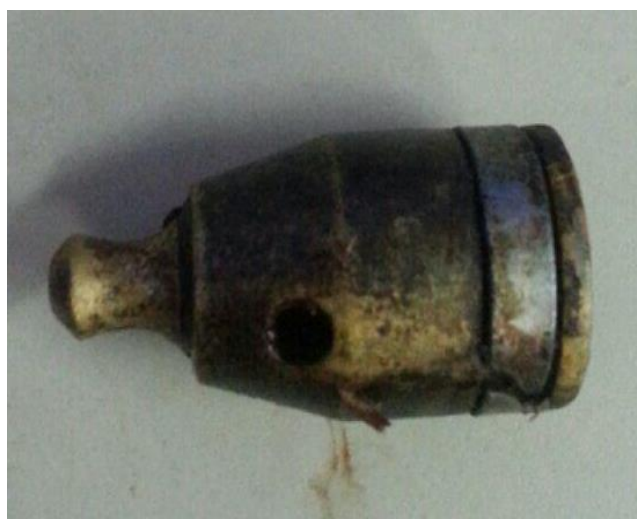

Figure 3: Foreign body that was removed

Intravenous methylprednisolone was started to lower the nerve swelling along with intravenous and topical antibiotics and adequate analgesia was given. On her very first post operative day she could perceive light from Right eye. She got better during her stay in the hospital with improved visiual acuity from no light perception to counting fingers by right eye. She was discharged with advice to follow up in ophthalmology clinic.

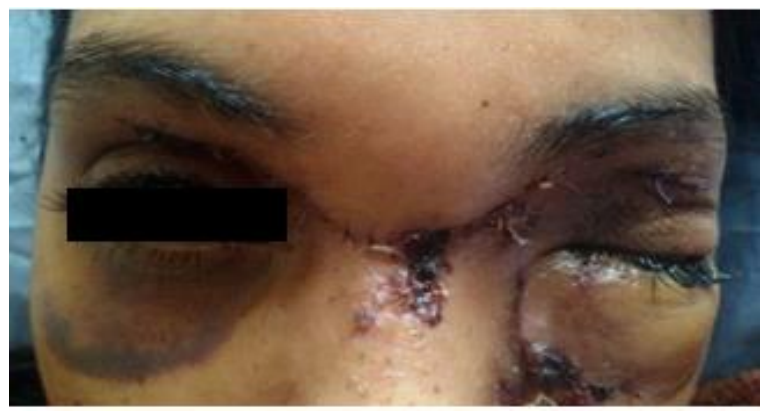

Figure 4: on 5th post operative day.

\section{Discussion:}

Eye is considered as a vital organ and sense of the human body as well. The adequate care and early management of the disease or trauma to the eye should be obtained. Worldwide, blindness in 1.6 million people is due to ocular trauma, 2.3 million are bilateral low-vision patients and 19 million people have unilateral blindness ${ }^{1}$. Ocular trauma is becoming relatively more 
important, especially in developing countries. The penetrating ocular trauma may lead complications range from traumatic cranial neuropathies to potentially fatal intracranial injuries ${ }^{2}$. Ocular complications include optic nerve damage resulting visual loss, extra-ocular muscle paralysis secondary to direct muscle trauma or nerve damage, proptosis or macular edema. Eye being close to paranasal sinuses, infection, specifically abscess formation is a common complication ${ }^{3}$.

The injuries that could be caused by using pressure cooker are multiple but the penetrating ocular trauma by pressure cooker nozzle is very rare $^{4}$. This type of incident could be deadly, so on to the emergency department; we should coordinate the multidisciplinary care of such patient with a penetrating eye injury ${ }^{5}$.

\section{Conclusion:}

Person handling such cooking utensil should be careful while cooking. They should be advised no to go nearby or bang it on floor when it doesn't blow whistle being on stove but one should switch off the heat to make it cool down first and only then start troubleshooting. The proper education and awareness should be provided for safety at home and emergency taking care of patients involved in such accidents should be prompt urgently.

\section{Consent:}

All the images and pictures were taken after verbal and written consent from patient and patient party with hiding the identity.

\section{References:}

1. Thylefors B, Aust N Z, Epidemiological patterns of ocular trauma, J Ophthalmol. 1992 May; 20(2):95-8.
2. Newman TL, Russo PA. Ocular sequelae of $\mathrm{BB}$ injuries to the eye and surrounding adnexa. J Am Optom Assoc. 1998;69(9):583-90.

3. Malla, Gyanendra et al. "Penetrating orbit injury: challenge to emergency medicine." BMC research notes vol. 6 493. 28 Nov. 2013, doi:10.1186/17560500-6-493

4. Viren Dobariya, Khushnood M Sheikh, Manisha Shastri, Sejal Desai, Manish Savani, , An Unusual Case of Penetrating Ocular Trauma with a Pressure Cooker Whistle, Delhi J Ophthalmol 2014; 24 (3): 207-208.

5. Havens S. Kosoko-Lasaki O, Palmer M. Penetrating eye injury: a case study. Am J Clin Med. 2009;6(1):42-49

6. Kinderan $\mathrm{YV}$ et al, Ocular trauma in western region of Nepal Pattern of ocular trauma in the Western Region of Nepal, Nepal J Ophthalmol 2012; 4(7):5-9.

7. Khatry SK, Lewis AE, Schein OD, Thapa MD, Pradhan EK, Katz J The epidemiology of ocular trauma in rural Nepal, , The British Journal of Ophthalmology. 2004;88(4):456-460.

8. Brilliant LB, Pokhrel RP, Grasset NC, Lepkowski JM, Kolstad A, Hawks W, Pararajasegaram R, Brilliant GE, Gilbert S, Shrestha SR. Epidemiology of blindness in Nepal. Bull World Health Organ. $\quad$ 1985;63(2):375-86. PMID: 3874717; PMCID: PMC2536402. 